\title{
The Build of Tourism Well-being Index System
}

\author{
Tianwen Zhang ${ }^{1}$ \\ ${ }^{1}$ Management School, Shanghai University of Engineering Science, China
}

Correspondence: Tianwen Zhang, Management School, Shanghai University of Engineering Science, China. E-mail: readygir19999@163.com

Received: November 13, 2013

Accepted: December 9, $2013 \quad$ Online Published: December 15, 2013

doi:10.5430/bmr.v2n4p110

URL: http://dx.doi.org/10.5430/bmr.v2n4p110

\begin{abstract}
The pursuit of happiness in life is our ultimate goal. In recent years, with the increasing income and leisure time, together with changes in consumer attitudes, tourism has become an important part in people's lives. This study constructed a model of tourism well-being index. Tourist well-being index includes comfortable, affordable, safe, novelty, satisfaction, a sense of worth and sense of happiness. In together they constitute tourist happiness index indicators. Rationally regulating the content of each index to build a comprehensive and easy-measured tourism Index System can not only improves the tourism discipline system and develops the tourism economy, but also has more important guiding significance for how to improve the national tourism well-being index.
\end{abstract}

Keywords: Well-being, Tourist well-being index, Tourist well-being, Exponential model

\section{Introduction}

Historical development of human society, in the final is the relentless pursuit of happiness in the process. Hedonism Happiness pedigree Epicuros (about 341 BC to 270 BC) said: "Happiness is the beginning and the purpose of our lives, we all have a happy choice of departure, our ultimate goal is to be happy." (Zheng Xifu, 2008) visibly, happiness is our ultimate goal in life. The world economic has rapidly increased since World War II, however, the improvement of people's happiness index was not so significant (Martin E.P.Seligman, 2012). So now there are economists suggest we should use Gross National Happiness (GNH) instead of Gross National Product (GNP) to measure the degree of social development. Tourism itself is a kind of activity well-related to well-being, which is the pursuit of a higher quality of leisure life when people have met basic needs (GaoYuan, Chen Xiaoyan. 2012). In recent years, as people's incomes, increased leisure time and changes in consumer attitudes, tourism has become an important part of people's lives. How to raise people's sense of well-being through tourism and how to measure the well-being index of tourists of tourism has become the focus of attention in tourism industry.

Tourism products include both tangible products and intangible products. We do not have methods and standards to evaluate the sense of happiness and well-being based on the purchase of travel products. This paper put forward a preliminary response to this problem. According to fieldwork, the authors find the main factors of tourism well-being index system, and improve the tourism Index System, which allows us to measure tourists' sense of happiness or well-being through the purchase of a tourism product.

\section{The relevant literature review}

\subsection{Well-being}

Happiness is an old topic, ancient philosophers began this quest what happiness is. Concerning the definition of happiness earliest trace to ancient Greece (Zou qiong, 2005), that time can be divided into two schools of happiness. Represented by Epicurus' hedonistic happiness theory "and Aristotle as the representative of the" doctrine to achieve happiness theory" (Zhu Cuiying,Fu Zaihan, 2009). Hedonistic happiness theory think people live on the purpose of the pursuit of happiness, well-being is the sum of joy and happiness they get (Miao Yuanjiang, 2009). Doctrine to achieve happiness theory notes that the happy life of happiness lies in the potential of human self-realization. In the 1960s, the study of WB (Well-being) began coming into view, Happiness research from philosophy into the psychology field (Ren Jun, 2012). Happiness research in psychological field is divided into two branches (SWB and PWB), SWB (Subject Well-being) Come from hedonistic happiness theory, while doctrine to achieve happiness theory evolved PWB (Psychology Well-being) (Lu Jia, Zhang Shu, 2011). SWB put happiness into two dimensions: 
Life satisfaction based on the cognitive appraisal and positive emotions / negative emotions based on emotional experience (Zeng Jia, 2008). Psychological well-being is mainly to explore the law of survival and existence of human life challenges (Zhang Yi, 2012). In recent years, there is a consolidation trend in the study of SWB and PWB, some scholars believe that the two complement each other to make a more comprehensive understanding of happiness profound (Wang Yan, Li Yue, Jin Yibo. 2010). Chen Haobin and Miao Yuanjiang believe that well-being is a multi-level, multi-dimensional structures, including subjective well-being, psychological well-being and social well-being of three factors (Chen Haobin, Miao Yuanjiang. 2012). Seligman, the founder of positive psychology, hold the view that well-being is constituted by the positive emotions, inputs, achievement, relationships, purpose and significance (Martin E.P. Seligman, 2011). Thus, the research on happiness has moved out of the jungle.

\subsection{The research of tourism and happiness or well-being}

Correlation researches directly on tourism and happiness or well-being are very rear, mostly about travel destinations resident happiness, happiness-based tourism economic research. These days with the development of experience economic, scholars are paying more attention to travel experience. But scholars have more perspective from tourism manager on tourists' satisfaction, few scholars study tourists happiness or well-being entirely from the standpoint of tourists (Kang Xiong, 2011). Abroad travel happiness research earlier than China. Ady Milman (1998) studied middle-aged tourists and found that tourism does not improve their psychological well-being (Ady Milman, 1998). Sebastian Filep (2010) believe that travel happiness is that tourists be in a positive emotional state, and be able to actively pursue the significance of tourism activities (Sebastian Filep, Margaret Deery, 2010). David Gilbert (2004) found that both of holiday tourists' before-travel and after-travel well-being are improved (David Gilbert, Junaida Abdullah. 2002). Jeroen Nawijn $(2010,2011)$ conducted comparative study on tourists and non-tourists , and found that in the preparation phase before traveling tourists have stronger sense of happiness than non-tourists, after returning from tour the two groups' happiness undifferentiated, and travel stress and attitudes towards tourism directly determines tourists happiness (Jeroen Nawijn, 2011)(Jeroen Nawijn, 2010). Salvatore Bimonte (2012) from the perspective of tourism and happiness economics studied tour types of tourists and their tourism happiness(Salvatore Bimonte, Valeria Faralla. 2012). Wang Wenyi, Wu Mingyuan (2012) studied the tourism impact on the individual subjective well-being and its evaluation system (Wang Wenyi, Wu Mingyuan. 2012). Kang Xiong (2013) argues that people travel is the pursuit of well-being, and that tourism well-being is possible, at the same time Kang Xiong $(2009,2010,2012)$ also built tourism well-being dimension (Kang Xiong, Ma Yaofeng. 2010)(Kang Xiong. 2012)(Kang Xiong, Kou Xiaolong. 2009). There are also some indirect studies respectively from angel of the leisure and well-being, the leisure and the quality of life and other aspects the research (Long Jiangzhi, Wang Su 2013)(Yu Yong,Tian Jinxia. 2013).

From the above view, travel happiness / well-being research is not very mature, we hope that through the establishment of tourism well-being index system, this paper serves practice, also contribute to perfect well-being of tourism research.

\section{Tourism well-being index system}

Tourism well-being index is a organic unity including satisfaction, perceived value, and happiness tourists get in the process of their consumption of tourism products. In tourism activities, people are not just passive acceptance. In which tourists can pay more attention to their experiences to their own value, and thus gain happiness/well-being.

Tourism well-being index the content covers the whole process of tourism, combining tourism six factors, should contain all kinds of psychological experience in the process of the food, accommodation, transportation, traveling, shopping, entertainment. Tourist satisfaction therefore be divided into comfortable, affordable, safe, novel, five index satisfaction. The index and value index, the index of happiness/well-being together form tourism well-being index system.

Comfort index mainly for physical and mental relaxation and pleasure. General requirements to eliminate a crowded, noisy, dirty environment, get thorough warm service.

Novel index reflects the degree of novelty tourists feel about their own experiences in the process of travel. Consumers tend to get different experience which is not the same with their life and then decide to choose what kind of tourism products, it is much more depends on the subjective feeling of people.

Safety index is different from other kinds of index, this index mainly through some negative examples, such as safety accidents and hidden danger in tourism consumption product security testing, to highlight. Tibet, for example, the 3.14 incident, the number of tourists to Tibet is loss sharply, seriously blow knocked the local tourism industry. 
Satisfaction index is a measure of tourists' satisfaction in the process of their tour. Most tourists want to show their own tourism and get recognition and admiration from others, so as to get a sense of pride.

Value index is the feeling of tourists get happiness in tourism activities, it is cognition and evaluation of their own role. It makes the tourism consumers no longer to accept the tourism product passively. But let them actively join the tourism activities, truly become the masters of tourism activities, and to experience their own value.

Happiness/well-being index is a measure of tourists subjective joyful feeling in the travel. Happiness is a comprehensive psychological feeling which is more than sense of comfort and relax, it higher requirements to the external environment condition. It is not only to achieve a satisfactory degree, but also touches tourism consumers' inner feelings.

\section{Tourism well-being index calculation model}

\subsection{Influencing factors of each index in the Travel happiness index system}

This paper listed tourism well-being index factors affecting the system in the deep understanding of the above tourism well-being content. It is made up of seven index above. The influence factors of each index differ with different tourism product. Listed below are usually important influence factors of each index for reference.

In the determination of a tourism product buyers' happiness/well-being, to find out the main influence factors on the basis of the condition of the products, and to make proper modification and supplement. In this way can we more full and accurate determination of the tourism well-being index of tourism.

\subsection{The measure of tourism happiness index}

\subsubsection{The two conditions}

First, we give seven index the same weight, as to improve the quality of the tourism consumers is an important way to improve the quality of tourism products. Many tourists' happiness/well-being also needs to be correct and improve. Tourism well-being is not only getting much material benefit, tourist may not get much mental and physical comfort and edify disposition at the same time. Tourism well-being does not mean getting a lot of novel experience, there could be a big security hidden danger in the tourism products. Therefore, based on improving the quality of tourists' happiness/well-being and sustained and healthy development of the tourism products, we give the seven index of the same weight.

Second, we give each index influencing factors of the same value. This is because , on the one hand, the characteristics of each tourism products is not the same, the influence factors of each index is also different, they cannot be treated as the same. On the other hand, there are many kinds of influence factors of each index in essence. In order to measure them simply, as long as we find out the most influence factors. Since they are the same important, we might as well give them the same weight.

\subsubsection{The calculation steps}

(1) According to the particular situation of tourist products to find out the main effect of each index value, draw table 1 happiness index factors in the tourism system.

(2) Tourism well-being questionnaire design. The economical index mentioned above is still the important factor decide whether people will be willing to buy a tourism product with in the unbalanced national income of our country. And because of the difference of income of the same travel products affordable index people also can have significantly different points of view. So in order to be able to more accurately reflect tourism consumers' happiness/well-being. When designing the questionnaire we must statistics visitors piecewise different levels of income.

The Likert scale method is adopted, the tourists subjective feeling to each index of main influence factors is divided into five levels, These five options corresponding to the following five options: very satisfied: $>90$ points, satisfaction: $75-90$ points: $60-75$ points are not satisfied: $45-60$ points means very unhappy: $<45$ points

(3) Adopt the method of random sampling questionnaire

(4) The recycling questionnaire statistical valid questionnaires

(5) Into the model calculation. According to the classification of different income levels of tourists, the value of the various influencing factors of each index is calculated, which stands for tourists on the influence factor of the average attitude, can reflect the most tourists experience value. 


$$
\mathrm{M}=\mathrm{L}+\frac{\Delta 1}{\Delta 1+\Delta 2}
$$

Then you get the weight of the influence factors of each index value in the following formula. $j$ stands for participant index,$k$ stands for participate in the main influence factors of index, as the main factors influencing the weight, and $i$ stands for grouping according to tourists different levels of income.

$$
P_{i}=\frac{1}{j} \sum_{i=1}^{j} \lambda\left(M j_{1}+M j_{2}+\cdots+M j_{k}\right)
$$

$P_{i}$ stands for tourism consumers' happiness/well-being index of each different income.

And then into the weighted arithmetic mean (so that you can put in different stages of the index and weight of their this twofold factors into consideration, so as to get a reasonable index value). $f_{i}$ stands for the income level of tourists in the proportion of all the tourists; $n$ stands for the passengers of the different income level and points.

$$
\mathrm{P}=\frac{P_{1} f_{1}+P_{2} f_{2}+\cdots+P_{i} f_{i}}{\sum_{i=1}^{n} f_{i}}
$$

P: tourism consumers' happiness/well-being index by buying a tourist product.

(6) Tthe result analysis. Combined with the Likert scale method, get the following conclusion:

1) When $P>=75$, the first level of satisfaction. This indicates that the tourism product has offers visitors a higher tourism happiness. The present situation should to maintain and improve the products. Its business model and idea is worth reference and popularization, which can provide more tourism consumers create a high degree of happiness.

2) When $60<\mathrm{P}<75$ points, the secondary satisfaction. The tourism products to provide tourists 'well-being just average. Need to compare various specific weights of affecting factors and to find out the key problem. And for the poor to make further investigation and analysis. Make improvement and restructuring measures actively, try to decrease and eventually eliminate these negative effects.

3) When $\mathrm{P}<=60$ points, the third level of satisfaction.

This indicates that the tourism product purchase of low value. At this time, the tourism industry should decide whether to continue to operate the product according to specific situation. The measure to improve the quality of the product or stop tourism products of the production of these two methods which can bring more benefit, make corresponding measures.

\section{Simple comments on the tourism happiness index system}

\section{1 evaluation of travel happiness index content}

The content of the tourism happiness index this article puts forward is quite complete and more accord with the idea of tourist happiness/well-being. With the improvement of people's living standard, the quality of the products for tourism consumption demand will be higher and higher. The index put forward above will not be able to comprehensively express people's travel happiness. Therefore, here is just to provide a reference model, we hope there will be higher level of development in tourism happiness study. 


\subsection{Evaluation of tourism happiness index calculation model}

Table 1. Travel happiness index system

\begin{tabular}{|c|c|c|}
\hline Index type & Primary factors & Secondary influence factors \\
\hline comfort index & $\begin{array}{l}\text { Transportation, accommodation, } \\
\text { catering, sightseeing, entertainment, } \\
\text { etc }\end{array}$ & $\begin{array}{l}\text { Transportation, time, the conditions of the } \\
\text { accommodation, environment, service, the taste } \\
\text { of food, weight, visit the Courier, the docent } \\
\text { service, etc }\end{array}$ \\
\hline Economical index & $\begin{array}{l}\text { Transportation, time, the conditions of } \\
\text { the accommodation, environment, } \\
\text { service, the taste of food, weight, visit } \\
\text { the Courier, the docent service, etc }\end{array}$ & $\begin{array}{l}\text { Traffic expenses, accommodation, meals, } \\
\text { admission fee, tour guide's explanation, tourist } \\
\text { souvenirs with price, etc }\end{array}$ \\
\hline Novel index & $\begin{array}{l}\text { Transportation, } \quad \text { sightseeing, } \\
\text { entertainment, etc }\end{array}$ & $\begin{array}{l}\text { Transportation and unique attractions, steep } \\
\text { degree, entertainment's unique way, schedules, } \\
\text { etc }\end{array}$ \\
\hline Safety index & $\begin{array}{l}\text { Transportation, accommodation, } \\
\text { catering, sightseeing, entertainment, } \\
\text { etc }\end{array}$ & $\begin{array}{l}\text { Traffic safety, the base of the fire security } \\
\text { measures, food hygiene, visit the hidden trouble } \\
\text { in security entertainment, etc }\end{array}$ \\
\hline Satisfaction index & $\begin{array}{l}\text { The evaluation of others, their own } \\
\text { gain a sense of pride, and so on }\end{array}$ & $\begin{array}{l}\text { Others for what they buy the attitude of the } \\
\text { tourism products, pictures, about buying } \\
\text { souvenirs and local specialty of tourism regional } \\
\text { other high and low, etc }\end{array}$ \\
\hline Perceived value index & $\begin{array}{l}\text { Get travel happiness for themselves in } \\
\text { the role of cognition and evaluation }\end{array}$ & $\begin{array}{l}\text { Degree of play to subjective initiative, the degree } \\
\text { of the master of tourism activities, the degree of } \\
\text { participation wish, master degree, etc }\end{array}$ \\
\hline Happiness index & $\begin{array}{l}\text { The outside world to build tourism } \\
\text { products, their own feelings }\end{array}$ & $\begin{array}{l}\text { Tourism environment, the quality of tourism } \\
\text { products, tourist's own emotion, acceptance of } \\
\text { tourism products, etc }\end{array}$ \\
\hline
\end{tabular}

This paper lists the indexes of general factors affecting tourist products. (As shown in table 1). The scope is wide, and measuring principle is basically the number that shall prevail. Mainly we can find the factors that influence the travel happiness from the measuring process, through which we can easily work out plans to improve tourism product and tourists' happiness.

\section{References}

Ady Milman. (1998). The Impact of Tourism and Travel Experience on Senior Travelers' Psychological Well-Being. Journal of travel research,1998(10):166-170. http://dx.doi.org/10.1177/004728759803700208

Chen Haobin, Miao Yuanjiang. (2012). The Relationship among Subjective Well-being, Psychological Well-being and Social Well-being. Psychological Research, 2012, 5(4):46-52.

David Gilbert \& Junaida Abdullah. (2002). A study of the impact of the expectation of a holiday on an individual's sense of well-being. Journal of Vacation Marketing, 2002(4):352-361. http://dx.doi.org/10.1177/135676670200800406 
GaoYuan \& Chen Xiaoyan. (2012). The Research on the Relationship between Tourism Economy and Destination Residents' Happiness. Journal of Fujian Institute of socialism,2012,4.

Jeroen Nawijn. (2011). Determinants of Daily Happiness on Vacation. Journal of Travel Research,2011(50):559-566. http://dx.doi.org/10.1177/0047287510379164

Jeroen Nawijn. (2010). Happiness is ... looking forward to your vacation Anonymous. Leisure \& Travel Week.

Kang Xiong \& Kou Xiaolong. (2009). On happy dimensions of traveling. Journal of Northwest University (Philosophy and Social Sciences Edition), 2009(06):185-186.

Kang Xiong \& Ma Yaofeng. (2010). Tourism How to become human happiness- And the Possibility of "Happiness" Tour. Philosophy dynamic, 2010(5):61-64.

Kang Xiong. (2012). Happiness on tourism and it's research value, perspectives and prospect. Ideological front. 2012:105-109.

Long Jiangzhi \& Wang Su. (2013). Serious leisure and happy life: A localization study based on Chinese senior group. Tourism Tribune, 2013(28):77-85.

Lu Jia \& Zhang Shu. (2011). Subject Well-being Research Review. Science \& Education, 2011, 3:118-119.

Martin E.P. Seligman. (2012). Flourish. Zhejiang People, s Publishing House,2012,11.

Kang Xiong. (2011). Study on tourists' well-being Based on ethical and psychological Perspective. Shaanxi Normal University,2011:14.

Martin E.P.Seligman. (2012). ZhaoYukun trans. Authentic Happiness. Zhejiang: Zhejiang People's Publishing House.

Miao Yuanjiang. (2009). Psychological Perspective happiness: happiness Theory and Measurement Research. Tianjin People's Publishing House.

Ren Jun. (2012). Positive Psychology. Kai Ming Publishing House, 2012, 6.

Salvatore Bimonte \& Valeria Faralla (2012).. Tourist types and happiness a comparative study in Maremma, Italy. Annals of Tourism Research, 2012(39):1929-1950. http://dx.doi.org/10.1016/j.annals.2012.05.026

Sebastian Filep \& Margaret Deery. (2010). Towards a picture of tourists' happiness. Tourism Analysis, 2010(13):399-410.

Wang Wenyi \& Wu Mingyuan. (2012). The impact of tourism on tourists' subject well-being and it's evaluation system. Economic management.

Wang Yan, Li Yue \& Jin Yibo. (2010). A Review on the Study of Well-Being. Psychological Research, 2010, 3(2):14-19.

Yu Yong, Tian Jinxia. (2013). A Research on Structural Relationship among Leisure Involvement, Leisure Benefits and Sense of Happiness for Bicycle Riders: A Case Study of Bike way Green Corridor Circling Star Lake in Zhaoqing. Tourism Tritune, 2013(02):67-76.

Zeng Jia. (2008). Subject Well-being Research Review. Journal of Xi'an Politics Institute, 2008,21(1):55-60.

Zhang Yi. (2012). Psychological well-being: the research method, influencing factors and prospect. Journal of Nanchang College of Education, 2012(7):143-144.

Zheng Xifu. (2008). Our happiness. Guangdong: Jinan University Press.

Zhu Cuiying \& Fu Zaihan. (2009). A Research Summary of Well-being. Journal of Hunan Agricultural University (Social Sciences), 2009(5):100-103.

Zou qiong. (2005). A Review of the Research on the Relation between Subjective Well-being and Culture. Psychological Science, 2005,28(3):632-633. 